\title{
Evaluation of the level of anxiety among pregnant women during the outbreak of Covid-19 Banuhan ŞAHIN ${ }^{1, ~(D), ~ D u y g u ~ M U R A T ~ O ̈ Z T U ̈ R K ~}{ }^{2, *}$ (i)
}

\author{
${ }^{1}$ Department of Gynecology and Obstetrics, Amasya University Sabuncuoglu Serefeddin Training and Research Hospital, Amasya Turkey \\ ${ }^{2}$ Department of Midwifery, Amasya University Health School, Amasya,Turkey
}

\begin{abstract}
\begin{tabular}{ccccc}
\hline Received: 29.08 .2020 & $\bullet$ & Accepted/Published Online: 16.12 .2020 & $\bullet$ & Final Version: 14.03 .2021 \\
\hline
\end{tabular}
\section{Abstract}

The aim of this study is to investigate the level of anxiety and distress among pregnant women during the outbreak of Covid-19. A 30-item questionnaire was applied on-line to a total of 240 pregnant women from all the cities of Turkey between 18-24 May 2020. With this questionnaire, demographic data of the participants, their knowledge and concerns about Covid-19, general measures they took against Covid-19, pregnancy follow-ups and their delivery preferences were evaluated. In addition, State-trait Anxiety Inventory (STAI) adapted to Turkish was applied to each participant. Personal and obstetric information were grouped and compared with anxiety scale. Anxiety levels of the groups were calculated. The STAI score means of 240 pregnant women who filled our questionnaire was $46.39 \pm 12.36$ and the Cronbach Alpha value was calculated as 0.93 . It was found that 125 pregnant women received help by contacting their doctor over the phone during the Covid-19 outbreak. It was also found that 106 pregnant women wanted to give birth at home. It was again found that $47.9 \%$ of pregnant women received information about Covid-19 from television. The STAI scores of pregnant women whose one or more family members' Covid-19 test were positive was $59.60 \pm 5.63$. The anxiety scores of pregnant women who were healthcare workers was $48.30 \pm 12.27$. Necessary clinical and psychological counselling services should be provided by local and national health institutions via television, telephone and internet for pregnant women, whose anxiety level increased during Covid-19 outbreak, to be in full physical and mental well-being.
\end{abstract}

Keywords: Coronavirus 2019, covid-19, pregnancy, anxiety

\section{Introduction}

The coronavirus 2019 disease (Covid-19) epidemic is an urgent public health problem of international concern and has directed states to take mandatory measures for the health of their people (Wilder-Smith et al., 2020). Following detection of the first case in Turkey on 10.03.2020, closure of schools and universities, curfew for citizens under twenty and over sixtyfive years old, making work shifts flexible, making wearing masks in public areas mandatory, restriction of travel to metropoles were taken as decisions by the government aimed at reducing the spread of the epidemic by the government (Republic of Turkey Ministry of Health Directorate General of Public Health, 2020). Many people have socially isolated themselves to prevent infection by staying at home. Public personnel who were pregnant were also permitted to be on leave during this period and were allowed to stay home.

It is known that infection outbreaks have a deep and wide range of psychosocial effects on individuals and communities (Wang et al., 2020). People experience feelings of helplessness, with the fear of getting sick and dying. Pregnant women are naturally more concerned because of the safety of their babies. In the past, some infectious diseases such as
SARS (severe acute respiratory failure syndrome) have been shown to exhibit a worse clinical course in pregnant women (Wong et al., 2004; Lam et al., 2004).

According to the World Health Organization (WHO), anxiety and depression disorders are considered as public health problems due to their high prevalence during pregnancy (Patel and Kleinman, 2003). The high prevalence of anxiety of Turkish women at the beginning of pregnancy was linked to some cultural features such as family structure (having more children and large families), Islamic religion or lack of spouse support in a research (González-Mesa et al., 2019). In a study of pregnant women in Turkey was found that $70 \%$ of them had anxiety and whether pregnancy was planned or not affected the anxiety score (Sel et al., 2019). In the study conducted by Arslan et al., $28.8 \%$ of the pregnant women had anxiety symptoms and $35.0 \%$ had depression symptoms (Arslan et al., 2011). Multiple researches suggest that prenatal stress may have long-term effects on gestational time and fetal growth, and may even be responsible for behavioural and cognitive changes (Ferreira et al., 2015; Ravid et al., 2018). Research is needed to develop evidence-based strategies to reduce the 
negative psychological effects and psychiatric symptoms of the Covid-19 outbreak on society. In this regard, research have been conducted on general society, medical students, children, healthcare workers and Covid-19 positive patient groups (Zhang et al., 2020; Cao et al. 2020; Al-Rabiaah et al., 2020; Lai et al., 2020). Yet, looking at the literature, no research investigating the psychological status of pregnant women during the Covid-19 outbreak has been encountered. The aim of this study is to measure the anxiety levels of pregnant women during the Covid-19 outbreak and to analyse the potential risk factors associated with pregnant women to perform routine follow-ups, treatments and deliveries safely.

\section{Materials and methods}

This study used descriptive cross-sectional design. As the Government of Turkey suggested citizens to minimize face to face interaction and to isolate themselves at home, potential participants were invited to take part electronically by the providers of the current research. This research was designed to measure the anxiety levels of women who were still pregnant during the Covid-19 outbreak using the online survey platform, Google Form, on May 18-24. A total of 240 pregnant women from all the cities of Turkey between the ages of 18-45 answered all the questions of the questionnaire on-line. The questionnaires were completed on a voluntary basis by the women whose pregnancies were still ongoing. The study was performed in accordance with the Declaration of Helsinki. All participants read and signed a written informed consent Ethical approval for the study was granted by Amasya University Ethics Committee (decision no: E.10138).

The structured questionnaire, inspired by previous research on the psychological effects of SARS and influenza outbreaks of pregnant women, consisted of questions covering several areas: (1) demographic data, (2) knowledge and concerns about Covid-19, (3) thoughts about birth preferences during the Covid-19 epidemic, (4) responds to the state-trait anxiety inventory (STAI) (Lee et al., 2006; Spielberger Gorsuch et al., 1971). Socio-demographic data consisted of age, education status, employment status, profession, family type, number of pregnancies, number of living children, gestational week, and presence of chronic disease. Within the scope of the information related to Covid-19 (1) the presence of Covid-19 positives/hospitalized relatives, (2) source of Covid-19 information followed, (3) general measures taken to protect from Covid-19, (4) presence of concerns about transmitting Covid-19 to their own babies were questioned. Among the measures taken against Covid-19, staying at home, washing hands frequently with soap, washing clothes over $600 \mathrm{C}$, not sharing personal items, ventilating the house/room frequently, cleaning the house constantly, keeping social distance, wearing a mask, wearing gloves, drinking plenty of fluids, consuming plenty of fruits, walking, not going to the hospital unless necessary, calling doctor and getting information, getting a flu shot were put forward. As preferences for delivery during the Covid-19 epidemic process, giving delivery at home, having caesarean, having preterm delivery, giving delivery in a hospital without Covid-19, giving delivery late if possible and having a normal delivery were listed.

STAI was applied to each participant. The STAI was first developed by Spielberger Gorsuch et al. (Spielberger Gorsuch et al., 1971). It is a Likert type scale consisting of 20 questions. It consists of four options as: 1) not at all, 2) somewhat so, 3) moderately so and 4) very much so. Cronbach's alpha value is between 0.83 and 0.92 . The Turkish validity and reliability of this scale, which determines how the individual feels at a certain moment and under certain conditions, was made by Oner and Le Compte in 1985 (Oner and Le Compte in 1985). Cronbach Alpha value of Turkish version was found between 0.94 and 0.96 . In calculation of the scale, positive scores (increasing the total anxiety score) are given for the items 3, 4, $6,7,9,12,13,14,17$, and 18 and negative scores (reducing total anxiety score) are given for items 1, 2, 5, 8, 10, 11, 15, 16, 19 and 20. Depending on whether it is negative or positive, 14 points are given to each item while scoring. Total score is obtained by adding 50 points to the score obtained. Anxiety level also increases as the score increases. A minimum of 20 or a maximum of 80 points can be obtained (Özusta, 1995).

The study data were statistically analyzed using IBM SPSS Statistics 21.0 (IBM Corp. Armonk, NY). Descriptive statistics (mean, median, standard deviation, minimum, maximum) were used for data analysis. Parametric tests were found applicable by considering the normality distribution. While T-test was used in two group comparisons, One-way Anova test was used in comparisons with more than two groups. Values with test results of $\mathrm{p}<0.05$ were statistically significant.

\section{Results}

Ages of the 240 pregnant women who completed our online survey were between 20 and 45 years, and the mean was 30.31 \pm 4.55 years. As seen in Table 1, $40.8 \%$ of pregnant women were between $26-30$ years old, $75 \%$ were university graduates, and $35 \%$ were on leave because of the Covid-19 outbreak. Among the employees, 29.2\% worked in the health sector, including doctors, dentists, dental hygienists, midwives, nurses, health officers and medical secretaries. Gestational weeks of the participants were between three and 41 weeks and they were on average $23.9 \pm 9.30$ weeks of gestation. $45 \%$ of pregnant women were in the second trimester. The number of pregnancies varied between the first and fifth pregnancies and the median was 2 . The median number of children living was 1. We learned that $184(76.7 \%)$ of pregnant women who completed the questionnaire went to the hospital in the last month before the Covid-19 outbreak. 123 (66.84\%) of those who went to the hospital in the past month stated that they went to routine pregnancy control. To the question of "What are you doing or do you do first if you have or happen to have a 
pregnancy or health condition during the Covid-19 outbreak?", $125(52.1 \%)$ pregnant women stated as "I call or send a message to my doctor", $52(21.7 \%)$ pregnant women stated as "I am going to the hospital", 25 (10.4\%) pregnant women stated as "I'm expecting the situation to pass", $13(5.4 \%)$ pregnant women stated as "I call or send a message to my midwife" and $9(3.8 \%)$ pregnant women stated as "I go to the district polyclinic." Knowledge of the pregnant women about Covid-19 during the Covid-19 outbreak is given in Table 2. Almost half of pregnant women stated that they received the information about Covid-19 from TV, while 27.1\% stated that they obtained it from social media. Almost all pregnant women stated that they were worried about Covid-19 infecting both her and her baby. To protect from Covid-19, pregnant women were found to take precautions like washing their hands frequently, washing the clothes over $60 \mathrm{C}$, not going to the hospital, not going out on the street, using only their own belongings, keeping social distance, ventilating the house frequently, calling the doctor and getting information, wearing a mask, constantly cleaning the house, wearing gloves, consuming plenty of fruit and consuming liquids. When they were questioned whether they made changes in their nutritional and exercise habits due to Covid-19 outbreak, it was found that $165(68.8 \%)$ pregnant women did not change their nutrition and $176(73.3 \%)$ pregnant women did not exercise.

Table 1: Personal and obstetric characteristics of pregnant women in the Covid-19 outbreak process

\begin{tabular}{|c|c|c|c|}
\hline \multirow{5}{*}{ Age (years) } & & $\mathbf{n}$ & $\%$ \\
\hline & $20-25$ years & 33 & 13.8 \\
\hline & $26-30$ years & 98 & 40.8 \\
\hline & $31-35$ years & 79 & 32.9 \\
\hline & 36 years and older & 30 & 12.6 \\
\hline \multirow{4}{*}{$\begin{array}{l}\text { Educational } \\
\text { Status }\end{array}$} & Primary School & 4 & 1.7 \\
\hline & Secondary School & 20 & 8.3 \\
\hline & High School & 36 & 15 \\
\hline & University & 180 & 75 \\
\hline \multirow{4}{*}{ Employment } & Employed & 48 & 20 \\
\hline & Unemployed & 86 & 35.8 \\
\hline & On maternity leave & 22 & 9.2 \\
\hline & On leave because of Covid-19 & 84 & 35 \\
\hline \multirow{4}{*}{ Occupations } & Healthcare workers & 70 & 29.2 \\
\hline & Educational workers & 49 & 20.4 \\
\hline & Unprofessional & 61 & 25.4 \\
\hline & Other profession groups & 60 & 25.0 \\
\hline \multirow{2}{*}{ Family type } & Nucleus family & 224 & 93.3 \\
\hline & Large family & 16 & 6.7 \\
\hline \multirow{2}{*}{$\begin{array}{l}\text { Number of } \\
\text { pregnancies }\end{array}$} & First pregnancy & 100 & 41.7 \\
\hline & Multiparous & 140 & 58.3 \\
\hline \multirow{2}{*}{$\begin{array}{l}\text { Children } \\
\text { alive }\end{array}$} & 0 & 106 & 44.2 \\
\hline & 1 or more & 134 & 55.8 \\
\hline \multirow{3}{*}{$\begin{array}{l}\text { Gestational } \\
\text { week }\end{array}$} & First Trimester & 39 & 16.3 \\
\hline & Second Trimester & 108 & 45 \\
\hline & Third Trimester & 93 & 38.8 \\
\hline \multirow{3}{*}{$\begin{array}{l}\text { Chronical } \\
\text { disease }\end{array}$} & Yes & 23 & 9.6 \\
\hline & No & 217 & 90.4 \\
\hline & Total & 240 & 100 \\
\hline
\end{tabular}

Variables presented as $\mathrm{n}(\%)$.

The thoughts of pregnant women regarding birth preferences in Covid-19 process are given in Table 3. The most frequent answer to the question of "What do you think about birth during the Covid-19 outbreak?" was "I want to give birth at home" and following it was "I want to have caesarean". In Table 4, thoughts of pregnant women about STAI scale items are presented. STAI score means are $46.39 \pm 12.36$, the minimum value is 20 and the maximum value is 75 . Cronbach Alpha score was calculated as 0.93 . STAI scores of groups created according to personal characteristics of pregnant women are shown in Table 5. In terms of age, the scale score was lower in the 20-25 age group and higher in the 31-35 age group ( $\mathrm{p}=0.003$ ). It was seen that the scale scores of workers in the field of health were higher than other groups, no statistically significance was detected $(\mathrm{p}=0.363)$. STAI scores of pregnant women in groups created according to Covid-19 knowledge are shown in Table 6. STAI scores were found to be statistically higher in those who were concerned about the infection of Covid-19 disease to both themselves and their babies $(p=0.000)$. 


\section{Discussion}

In this cross-sectional research we conducted between April 1 to 7 , by reaching 240 pregnant women and investigating their anxiety levels during the Covid-19 outbreak, we found that the anxiety levels of the pregnant women were high. We learned that they were afraid to go to the hospital during the Covid-19 outbreak, that if they went, they were afraid that the virus would infect themselves and therefore their babies, so they reached out to their doctors by phone and received help and wanted to give birth at home. Anxiety levels of pregnant women at least one of whose family members were positive for Covid-19 test were higher than others. Additionally, anxiety levels of pregnant women who were healthcare workers were higher than others. Pregnancy status brings happiness, hope and well-being to women and other individuals in the family in general. However, some women may experience fear and anxiety in family, social and work environments due to the physical and mental changes that naturally develop during pregnancy. Anxiety causes of pregnant women may include feelings of vulnerability, loss of control and concerns about non-isolation (National Institute for Health and Care Excellence, 2014). Separations, losses, displacements and epidemic diseases experienced during pregnancy can affect the negative psychology which already lays background of the pregnant women and cause them to become depressed easily (Mahmoud et al., 2016). Covid-19 may be transmitted from person to person; associated with high morbidity and being potentially fatal, it can intensify personal perception of danger (Xiang, 2020). Pregnant women are at a higher risk for Covid19 virus like all viral infections compared to non-pregnant women (Dashraath et al., 2020). Although transmission of the virus to the fetus has not been detected in recent publications, babies who have positive Covid-19 tests are encountered (Schwartz and Graham, 2020). Anxiety levels of pregnant women who see this information both on television and social media naturally increase. One of the remarkable results in the research is that the anxiety levels of pregnant women aged 2025 are statistically lower. This reminds us of the emphasis mentioned in the media that the disease does not occur at a young age, or that the symptoms of the disease are less and are more moderate. The fact that there is no difference between the groups in terms of education levels also shows that pregnant women are anxious regardless of their educational status. Although it is not statistically significant, it may be observed that the anxiety levels of pregnant women in the last trimester are higher than the women with pregnancy in the other trimesters. Here, we think that anxiety increases as the time of birth approaches.

Table 2: Knowledge of pregnant women about Covid-19 during the Covid-19 outbreak

\begin{tabular}{|c|c|c|c|}
\hline Knowledge & & $\mathbf{n}$ & $\%$ \\
\hline \multirow{2}{*}{$\begin{array}{l}\text { Is the Covid- } 19 \text { test result positive for } \\
\text { you or one of your relatives? }\end{array}$} & Yes & 5 & 2.1 \\
\hline & No & 235 & 97.9 \\
\hline \multirow{3}{*}{$\begin{array}{l}\text { Do you have a hospitalised acquaintance } \\
\text { because of Covid-19? }\end{array}$} & Yes & 11 & 4.6 \\
\hline & No & 229 & 95.4 \\
\hline & Television & 115 & 47.9 \\
\hline \multirow{3}{*}{$\begin{array}{l}\text { Where do you follow the information } \\
\text { about Covid-19 the most? }\end{array}$} & Social media & 65 & 27.1 \\
\hline & $\begin{array}{l}\text { Official webpage of } \\
\text { the Ministry of Health }\end{array}$ & 51 & 21.3 \\
\hline & Other & 9 & 3.7 \\
\hline \multirow{2}{*}{$\begin{array}{l}\text { Are you worried about being infected by } \\
\text { Covid-19? }\end{array}$} & Yes & 225 & 93.8 \\
\hline & No & 15 & 6.3 \\
\hline \multirow{2}{*}{$\begin{array}{l}\text { Are you worried about Covid-19 } \\
\text { infecting your baby? }\end{array}$} & Yes & 226 & 94.2 \\
\hline & No & 14 & 5.8 \\
\hline
\end{tabular}

Table 3. Opinions of pregnant women on delivery preferences during the Covid-19 outbreak

\begin{tabular}{|lcc|}
\hline Delivery preferences & $\mathbf{n}$ & $\mathbf{\%}$ \\
\hline I would like to give birth at home. & 106 & 44.2 \\
\hline I would like to have caesarean. & 52 & 21.7 \\
\hline I would like to give birth in a safe, sterile, precautionary hospital. & 12 & 5.0 \\
\hline I would like to give normal delivery. & 16 & 6.7 \\
\hline I would like to give preterm birth. & 23 & 9.6 \\
\hline I want to give birth in a hospital without Covid-19. & 6 & 2.5 \\
\hline I would give birth late if I could. & 6 & 2.5 \\
\hline I have more time to give birth. & 6 & 2.5 \\
\hline Other & 13 & 5.4 \\
\hline Total & 240 & 100 \\
\hline
\end{tabular}

Variables presented as $\mathrm{n}(\%)$ 
Table 4. STAI scores of pregnant women during the Covid-19 outbreak process

\begin{tabular}{|c|c|c|c|c|c|c|c|c|}
\hline \multirow[t]{2}{*}{ STAI } & \multicolumn{2}{|c|}{ NOT AT ALL } & \multicolumn{2}{|c|}{$\begin{array}{l}\text { SOMEWHAT } \\
\text { SO }\end{array}$} & \multicolumn{2}{|c|}{ MODERATELY SO } & \multicolumn{2}{|c|}{ VERY MUCH SO } \\
\hline & $\mathrm{n}$ & $\%$ & $\mathrm{n}$ & $\%$ & $\mathrm{n}$ & $\%$ & $\mathrm{n}$ & $\%$ \\
\hline I'm calm right now & 20 & 8.3 & 70 & 29.2 & 84 & 35 & 66 & 27.5 \\
\hline I feel safe & 31 & 12.9 & 81 & 33.8 & 81 & 33.8 & 47 & 19.6 \\
\hline I'm nervous right now & 90 & 37.5 & 68 & 28.3 & 58 & 24.2 & 24 & 10 \\
\hline I feel a sense of regret & 170 & 70.8 & 44 & 18.3 & 19 & 7.9 & 7 & 2.9 \\
\hline I'm at peace right now & 42 & 17.5 & 77 & 32.1 & 81 & 33.8 & 40 & 16.7 \\
\hline I'm out of sorts right now & 76 & 31.7 & 78 & 32.5 & 56 & 23.3 & 30 & 12.5 \\
\hline $\begin{array}{l}\text { I'm worried about what will happen } \\
\text { to me }\end{array}$ & 19 & 7.9 & 61 & 25.4 & 88 & 36.7 & 72 & 30 \\
\hline I feel rested & 47 & 19.6 & 70 & 29.2 & 71 & 29.6 & 52 & 21.7 \\
\hline I'm anxious right now & 30 & 12.5 & 66 & 27.5 & 78 & 32.5 & 66 & 27.5 \\
\hline I feel comfortable & 46 & 19.2 & 106 & 44.2 & 57 & 23.8 & 31 & 12.9 \\
\hline I have confidence in myself & 10 & 4.2 & 77 & 32.1 & 82 & 34.2 & 71 & 29.6 \\
\hline I've got nervous right now & 102 & 42.5 & 70 & 29.2 & 50 & 20.8 & 18 & 7.5 \\
\hline I'm very angry & 124 & 51.7 & 67 & 27.9 & 36 & 15 & 13 & 5.4 \\
\hline I feel I'm on the edge & 109 & 45.4 & 70 & 29.2 & 43 & 17.9 & 18 & 7.5 \\
\hline I feel relieved & 53 & 22.1 & 98 & 40.8 & 62 & 25.8 & 27 & 11.3 \\
\hline I am pleased with myself right now & 52 & 21.7 & 79 & 32.9 & 68 & 28.3 & 41 & 17.1 \\
\hline I am worried right now & 35 & 14.6 & 80 & 33.3 & 79 & 32.9 & 46 & 19.2 \\
\hline I feel stunned by excitement & 131 & 54.6 & 74 & 30.8 & 24 & 10 & 11 & 4.6 \\
\hline I'm happy now & 81 & 33.8 & 92 & 38.3 & 50 & 20.8 & 17 & 7.1 \\
\hline I'm in a good mood right now & 54 & 22.5 & 84 & 35 & 67 & 27.9 & 35 & 14.6 \\
\hline
\end{tabular}

STAI: State-trait anxiety Inventory. Variables presented as n (\%)

In this research, very few pregnant women had a Covid-19 positive relative $(2.1 \%)$, but the anxiety levels of these pregnant women were higher than those whose relatives were not positive. Here, the individuals were concerned about the transmission of the virus in the family to themselves, and therefore to the fetus.

Almost half of the pregnant women stated that they obtained information about Covid-19 through the television (47.9\%). We think that it is important for the minister of health to regularly explain the number of daily tests, cases, deaths, and improvements on television screens every evening. In addition, it's also important to give information in regular broadcasts on television channels about the spread of Covid-19 virus in the world and in Turkey, its symptoms, development of drugs/vaccines, travel recommendations, precautions taken, or more specific information (for example, for people with chronic diseases).

It was observed among the pregnant women participating in the questionnaire as measures taken by them, that almost all of them wash their hands with soapy water frequently, most of them never go out, comply with social distance measures and wear masks, and most of them pay attention to space and personal hygiene. It was concluded that most of the pregnant women were afraid to go to the hospital except for emergencies, they wanted to get information by contacting their doctor by phone or internet. In Turkey, nearly all hospitals across the country serve as pandemic hospitals. Therefore, it seems a natural behaviour for pregnant women to avoid hospital for routine pregnancy checks. With the recommendation of the Ministry of Health and the Turkish Society of Gynaecology and Obstetrics, intervals between routine pregnancy follow-ups may be prolonged, but important visits such as screening tests and fetal anomaly screening should never be skipped. It was found that pregnant women consumed plenty of fluids, eat plenty of fruits, but they did not exercise such as walking, paying attention to their diet during the Covid-19 epidemic. In this regard, we think that it is necessary to provide home exercise counselling on television channels such as yoga and pilates. With our research, we found that pregnant women also avoid from having a flu vaccine. This may be due to the vaccine being in the design phase and not having enough information in terms of effectiveness and side effects. Almost half of the pregnant women whose opinions about birth preferences were questioned during the Covid-19 epidemic were found to want to give birth at home. Although one fifth of the pregnant women wanted to have caesarean, those who had thoughts such as preterm delivery or delaying delivery were much less. Here, we understand that pregnant women want to stay away from pandemic hospitals where Covid-19 cases are followed up and treated. These people may think that they can contact individuals with positive Covid-19 tests, or that they may get this virus from healthcare professionals who are caring them. Health authorities should identify high-risk pregnant groups based on socio-demographic information for early psychological interventions. Our data show that pregnant women having relatives with positive Covid-19 test and pregnant healthcare workers have higher anxiety levels. These findings can be eliminated with active filiation detection, quarantine and, if 
necessary, treatment of people with a Covid-19 test. And yet, pregnant health workers worry that their leave will be terminated and called up at any time, even though they are not actively involved in the outbreak. It may be beneficial for the government to promise a leave guarantee until the outbreak is over. In addition, health officials can provide psychoeducation and psychological interventions (such as cognitive behavioural therapy) in the form of on-line information sharing by staying at home instead of face-to-face interviews to reduce the risk of virus transmission.

Table 5. STAI scorings in subgroups of personal and obstetric knowledge of pregnant women during the Covid-19 outbreak process

\begin{tabular}{|c|c|c|c|c|}
\hline & & $\begin{array}{c}\text { Anxiety Inventory Mean } \\
\text { Scores }\end{array}$ & $\mathbf{F}$ & $\mathbf{p}$ \\
\hline \multirow{4}{*}{ Age } & $20-25$ years & $40.87 \pm 11.29$ & \multirow{4}{*}{4.46} & \multirow{4}{*}{$0.005^{*}$} \\
\hline & $26-30$ years & $45.53 \pm 11.39$ & & \\
\hline & $31-35$ years & $49.74 \pm 12.81$ & & \\
\hline & 36 years and older & $46.43 \pm 13.26$ & & \\
\hline \multirow{4}{*}{ Educational Status } & Primary School & $53.75 \pm 8.77$ & \multirow{4}{*}{1.93} & \multirow{4}{*}{0.106} \\
\hline & Secondary School & $42.75 \pm 11.47$ & & \\
\hline & High School & $43.77 \pm 11.37$ & & \\
\hline & University & $46.40 \pm 12.31$ & & \\
\hline \multirow{4}{*}{ Employment } & Employed & $49.54 \pm 10.27$ & \multirow{4}{*}{1.82} & \multirow{4}{*}{0.143} \\
\hline & Unemployed & $44.95 \pm 12.69$ & & \\
\hline & On maternity leave & $49.04 \pm 11.47$ & & \\
\hline & On leave because of Covid-19 & $45.88 \pm 12.88$ & & \\
\hline \multirow{4}{*}{ Occupations } & Healthcare workers & $48.30 \pm 12.27$ & \multirow{4}{*}{1.07} & \multirow{4}{*}{0.363} \\
\hline & Educational workers & $45.42 \pm 12.65$ & & \\
\hline & Unprofessional & $44.65 \pm 12.34$ & & \\
\hline & Other profession groups & $46.71 \pm 12.24$ & & \\
\hline \multirow{2}{*}{ Family type } & Nucleus family & $46.64 \pm 12.27$ & \multirow[b]{2}{*}{1.38} & \multirow[b]{2}{*}{0.240} \\
\hline & Large family & $42.87 \pm 13.50$ & & \\
\hline \multirow{2}{*}{$\begin{array}{l}\text { Number of } \\
\text { pregnancies }\end{array}$} & First pregnancy & $45.24 \pm 11.63$ & \multirow{2}{*}{2.22} & \multirow{2}{*}{0.224} \\
\hline & Multiparous & $47.21 \pm 12.84$ & & \\
\hline \multirow{2}{*}{ Children alive } & 0 & $45.22 \pm 11.98$ & \multirow{2}{*}{0.777} & \multirow{2}{*}{0.379} \\
\hline & 1 or more & $47.31 \pm 12.63$ & & \\
\hline \multirow{3}{*}{ Gestational week } & First Trimester & $45.20 \pm 12.73$ & \multirow{3}{*}{1.709} & \multirow{3}{*}{0.166} \\
\hline & Second Trimester & $45.16 \pm 12.66$ & & \\
\hline & Third Trimester & $48.31 \pm 11.74$ & & \\
\hline \multirow{7}{*}{$\begin{array}{l}\text { Thoughts on Delivery } \\
\text { Preference }\end{array}$} & $\begin{array}{l}\text { I would like to give birth at home. } \\
\text { I would like to have caesarean. } \\
\text { I would like to give birth in a safe, sterile, precautionary } \\
\text { hospital. }\end{array}$ & $\begin{array}{c}47.03 \pm 13.07 \\
48.44 \pm 12.32 \\
44.41 \pm 7.47\end{array}$ & \multirow{7}{*}{1.352} & \multirow{7}{*}{0.219} \\
\hline & I would like to give normal delivery. & $44.37 \pm 8.49$ & & \\
\hline & I would like to give preterm birth. & $46.56 \pm 11.57$ & & \\
\hline & I want to give birth in a hospital without Covid-19. & $51.16 \pm 5.19$ & & \\
\hline & I would give birth late if I could. & $45.33 \pm 14.85$ & & \\
\hline & I have more time to give birth. & $38.16 \pm 20.37$ & & \\
\hline & Other & $39.00 \pm 10.28$ & & \\
\hline
\end{tabular}

$* \mathrm{p}<0.01$

The limitation of our research is that pregnant women were reached only on-line. Thus, only the data of pregnant women who are literate and can use the internet could be evaluated. Another limitation of our research is that it does not have a longitudinal course. Answers to STAI may change as pregnancy progresses and the condition of the Covid-19 outbreak worsens.

We think that our research will guide the development of interventions that can improve the psychological status of pregnant women and minimize anxiety levels during the Covid-19 outbreak locally and nationally. Thus, in the rest of the epidemic, success can be achieved in the stages of preventing, controlling and treating possible Covid-19 infection of pregnant women.

In conclusion, anxiety levels of pregnant women are high during the Covid-19 epidemic. Anxiety levels of pregnant women who have relatives with positive Covid-19 test and the ones who are health workers are higher. Pregnant women decrease their routine pregnancy controls due to the anxiety that Covid-19 infects themselves and their babies. There is a need for clinical and psychological counselling services to be provided by a team of midwives, obstetricians and 
psychologists online to ensure healthy pregnancy follow-ups and safe births of all pregnant women during the Covid-19 epidemic.

\section{Acknowledgements}

Authors would like to thank İbrahim Türker for English translation of the manuscript.

\section{Declaration of interest}

This case report has no conflict of interest

\section{References}

1. Al-Rabiaah, A., Temsah, M.H., Al-Eyadhy, A.A., Hasan, G.M., AlZamil, F., Al-Subaie, S. Alsohime F., Jamal, A., Alhaboob, A., AlSaadi, B., Somily, A.M., 2020. Middle East Respiratory SyndromeCorona Virus (MERS-CoV) associated stress among medical students at a university teaching hospital in Saudi Arabia. J. Infect. Public. Health. 13(5), 687-691.

2. Arslan, B., Arslan, A., Kara, S., Öngel, K., \& Mungan, M. T., 2011. Risk factors for pregnancy anxiety and depression: assessment in 452 cases. Journal of Tepecik Education and Research Hospital. 21(2), 79-84.

3. Cao, W., Fang, Z, Hou, G., Han, M., Xu, X., Dong, J., Zheng, J., 2020. The psychological impact of the COVID-19 epidemic on college students in China. Psychiatry. Res. 287, 112934.

4. Dashraath, P., Jing Lin Jeslyn, W., Mei Xian Karen, L., Li Min, L., Sarah, L., Biswas, A., Arjandas Choolani, M., Mattar, C., Lin, S.L., 2020. Coronavirus Disease 2019 (COVID-19) Pandemic and Pregnancy. Am. J. Obstet. Gynecol. 222(6):521-531.

5. Ferreira, C.R., Orsini, M.C, Vieira, C.R., Do Amarante Paffaro, A.M., Silva, R.R., 2015. Prevalence of anxiety symptoms and depression in the third gestational trimester. Arch. Gynecol. Obstetri. 291(5), 999-1003.

6. González-Mesa, E., Kabukcuoglu, K., Körükcü, O., Blasco, M., Ibrahim, N., Cazorla-Granados, O., Kavas T., 2019. Correlates for state and trait anxiety in a multicultural sample of Turkish and Spanish women at first trimester of pregnancy. J. Affect. Disord. 249, 1-7.

7. Lai, J., Ma, S., Wang, Y., Cai, Z., Hu, J., Wei, N., Wu, J., Du, H., Chen, T., Li, R., Tan, H., Kang, L., Yao, L., Huang, M., Wang, H., Wang, G., Liu, Z., Hu, S., 2020. Factors associated with mental health outcomes among health care workers exposed to coronavirus disease 2019. JAMA Netw Open. 3(3), e203976.

8. Lam, C.M., Wong, S.F., Leung, T.N., Chow, K.M., Yu, W.C., Wong, T.Y., Lai, S.T., Ho, L.C. 2004. A case-controlled study comparing clinical course and outcomes of pregnant and nonpregnant women with severe acute respiratory syndrome. BJOG. $111,771-774$.

9. Lee, D.T., Sahota, D., Leung, T.N., Yip, A.S., Lee, F.F., Chung, T.K., 2006. Psychological responses of pregnant women to an infectious outbreak: a case-control study of the 2003 SARS outbreak in Hong Kong. J. Psychosom Res. 61(5), 707-713.

10. Leung, G.M., Ho, L.M., Chan, S.K., Ho, S.Y., Bacon-Shone, J., Choy, R.Y., Hedley, A.J., Lam, T.H., Fielding, R. 2005. Longitudinal assessment of community psycho-behavioural responses during and after the 2003 outbreak of severe acute respiratory syndrome in Hong Kong. Clin. Infect. Dis. 40, 17131720.
11. Mahmoud, T., Mercer, C., Tschudin, S., Bitzer, J., GonzalesMesa, E., Rowe, H., et al., 2016. Perinatal mental health: Bridging the gaps in policy and practice. Entre. Nous. 85, 22-24.

12. National Institute for Health and Care Excellence, 2014. Antenatal and Postnatal Mental Health: Clinical Management and Service Guidance. Clin. Guidel. London, NICE, 2014.

13. Oner, N., Le Compte, W. 1985. Durumluk-Sürekli Kaygi Envanteri El Kitabi (Handbook of State-Trait Anxiety Inventory). İstanbul. Bogaziçi University.

14. Özusta, H., 1995. State-trait anxiety inventory for children adaptation, validity and reliability study. Turkish J. Psychol. 10, $32-44$.

15. Patel, V., Kleinman, A., 2003. Poverty and common mental disorders in developing countries. Bull WHO. 81, 609-615.

16. Ravid, E., Salzer, L., Arnon, L., Eisner, M., Wiznitzer, A., Weller, A., Koren, L., Hadar, E., 2018. Is there an association between maternal anxiety propensity and pregnancy outcomes? BMC Pregnancy Childbirth. 18(1), 287.

17. Republic of Turkey Ministry of Health Directorate General of Public Health. 2020. Covid-19 (2019-N Cover Disease) Guide, Science Study Committee, Accessibility. https://hsgm.saglik.gov.tr/depo/birimler/Bulasici-hastaliklar db

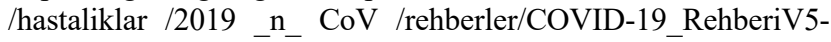
25February2020.pdf

18. Schwartz, D.A., Graham, A.L., 2020. Potential Maternal and Infant Outcomes from (Wuhan) Coronavirus 2019-nCoV Infecting Pregnant Women: Lessons from SARS, MERS, and Other Human Coronavirus Infections. Viruses. 12(2):194.

19. Sel, G., Barut, A., Solak, S., Uslu, S., Gedik, Y., Uzunoğlu, S., \& Barut, Z. S., 2019. The factors having an impact on anxiety among pregnant women. Journal of Continuing Medical Education 28(5), 334-339.

20. Spielberger Gorsuch, R.L., Lushene, R., Vagg, P.R., Jacobs, G.A., 1971. Development of the Spanish edition of the state-trait anxiety inventory. Rev. Interam. Psicol. 5, 145-158.

21. Wang, C., Pan, R., Wan, X., Tan, Y., Xu, L., Ho, C.S., Ho, R.C., 2020. Immediate psychological responses and associated factors during the initial stage of the 2019 coronavirus disease (COVID19) epidemic among the general population in China. Int. J. Environ. Res. Public Health. 17(5), 1729.

22. Wilder-Smith, A., Chiew, C.J., Lee, V.J., 2020. Can we contain the Covid-19 outbreak with the same measures as for SARS? Lancet Infectious Diseases. 20 (5), 102-107.

23. Wong, S.F., Chow, K.M., Leung, T.N., Ng, W.F., Ng, T.K., Shek, C.C. Ng PC, Lam PW, Ho LC, To WW, Lai ST, Yan WW, Tan PY. 2004. Pregnancy and perinatal outcomes of women with severe acute respiratory syndrome. Am. J. Obstet. Gynecol. 191, 292-297.

24. Xiang, Y.T., 2020. Timely mental health care for the 2019 novel coronavirus outbreak is urgently needed. Lancet Psychiatry. 7, 228-229.

25. Zhang, Y., Ma, Z.F., 2020. Impact of the COVID-19 pandemic on mental health and quality of life among local residents in Liaoning province, China: A cross-sectional study. Int. J. Environ. Res. Public Health. 17(7), 2381. 